\title{
EVALUASI TATAKELOLA INFRASTRUKTUR TI DENGAN FRAMEWORK COBIT 5 (STUDI KASUS: STMIK-STIE MIKROSKIL)
}

\author{
Elly $^{1)}$ dan Fandi Halim ${ }^{2)}$ \\ ${ }^{1,2}$ Sistem Informasi, STMIK Mikroskil \\ 1,2 Jl. Thamrin No. 112, 124, 140, Medan, 20212 \\ E-mail : ellyjong85@gmail.com ${ }^{1)}$, fandi@ @ikroskil.ac.id ${ }^{2)}$
}

\begin{abstract}
ABSTRAK
Evaluasi tatakelola infrastruktur TI menggunakan framework COBIT 5, studi kasus pada STMIK-STIE Mikroskil di Medan yang bertujuan untuk mengevaluasi infrastruktur TI yang diadopsi dan digunakan oleh sekolah tinggi apakah telah memenuhi standar framework COBIT 5. Evaluasi dilakukan oleh Pusat Sistem Informasi (PSI) sebagai pusat manajemen data. Data dikumpulkan lewat wawancara, kuesioner dan pemeriksaan dokumen, observasi dan investigasi kinerja. Sepuluh proses dalam lima domain - EDM, APO, BAI, DSS dan MEA - dievaluasi menggunakan Process Assessment Model (PAM) seperti yang ditentukan oleh ISACA. Rentang skor dari Level 0 (Non-existent) sebagai skor terendah menuju Level 5 (Optimizing) sebagai skor tertinggi. Skor dikumpulkan kemudian diterjemahkan ke dalam domain COBIT 5 dalam bentuk evaluasi penilaian kapabilitas untuk setiap domain. Penelitian menunjukkan saat ini STMIK-STIE Mikroskil memiliki beberapa hasil. Pertama, ada lima proses mencapai level 1 seperti EDM02, EDM04, APO04, BAI02, MEA01. Kedua, ada empat proses mencapai level 3 seperti EDM01, APO01, APO03, APO07. Ketiga, dan ada satu proses mencapai target level 4 seperti DSS05.
\end{abstract}

Kata Kunci: Tatakelola, COBIT 5, Process Assessment Model, Skor Kapabilitas.

\section{PENDAHULUAN}

Teknologi informasi menjadi bagian penting dari organisasi. Penerapan sistem teknologi informasi akan bermanfaat jika sesuai dengan tujuan, visi dan misi organisasi yang telah diterjemahkan ke dalam strategi bisnis dan strategi sistem teknologi informasi. Keselarasan antara strategi teknologi informasi dan strategi bisnis akan memberikan nilai tambah berupa competitive advantage dalam persaingan bisnis.

STMIK-STIE Mikroskil memiliki sebuah bagian yang bertugas melaksanakan pengembangan, implementasi dan perawatan perangkat keras, sistem informasi dan perangkat jaringan komputer yaitu Pusat Sistem Informasi. Visi yang dimiliki oleh Pusat Sistem Informasi dalam mendukung visi STMIK-STIE Mikroskil adalah menjadi perguruan tinggu yang unggul lewat pemanfaatan teknologi informasi dan komunikasi di Sumatera Utara. Dengan evolusi dari sistem informasi dan teknologi informasi banyak organisasi mendasarkan aktifitasnya pada sistem teknologi, dengan kata lain sistem informasi dan teknologi menjadi penting untuk memastikan sebuah performansi yang baik dan efisiensi kepada organisasi (www.mikroskil.ac.id/psi).

Infrastruktur TI adalah sebuah aset jangka panjang, nilai jangka panjang dari shareholder dan merepresentasikan pilihan jangka panjang dari suatu organisasi (Chanopas, Krairit, \& Khang, 2006).

Pengelolaan infrastruktur TI yang sesuai dengan standar yang berlaku terhadap pemanfaatan TI pada organisasi sangat penting untuk dilakukan. Hal ini terlihat karena departemen TI pada organisasi saat ini sering kali menghadapi masalah yang rumit terkait dengan tatakelola infrastruktur TI. Adapun masalah yang sering muncul antara lain disalokasi anggaran perusahaan dalam memenuhi infrastruktur TI, infrastruktur yang ada tidak sesuai dengan strategi bisnis organisasi sehingga infrastruktur TI menjadi sumber masalah dalam pengelolaan TI, minimnya maintenance infrastruktur TI pada organisasi dikarenakan anggaran yang terbatas, minimnya maintenance menyebabkan infrastruktur yang ada tidak dapat digunakan dalam jangka waktu yang lama. Maka untuk mereduksi permasalahan-permasalahan tersebut diperlukan suatu tatakelola infrastruktur TI yang mampu menjamin perbaikan secara efektif dan efisien dari proses bisnis yang terkait dengan infrastruktur TI.

Keberadaan tatakelola TI mampu mengembangkan pengaplikasian teknologi dan pemenuhan kebutuhan akan informasi yang dapat diandalkan dan terjamin. Tatakelola TI pada dasarnya merupakan serangkaian proses untuk mengarahkan dan mengontrol organisasi agar tujuan bisnis dapat dicapai melalui penambahan nilai sekaligus penyeimbangan resiko terkait dengan pengelolaan proses TI termasuk dukungan secara optimal yang diberikan oleh sumber daya TI terhadap pemenuhan tujuan bisnis (Sarno, 2009). Hal yang sama juga diutarakan dalam (Purnomo, et al., 2016) bahwa tatakelola teknologi informasi mempunyai peranan yang penting dalam memaksimalkan pemanfaatan teknologi informasi yang sudah diimplementasikan oleh organisasi guna menyesuaikan strategi TI dengan strategi bisnis organisasi. 
Optimalisasi sumber daya TI sesuai standar dapat dicapai dengan menggunakan framework yang disebut COBIT (Control Objectives for Information and related Technology) di mana COBIT merupakan sebuah kerangka kerja TI yang diinisiasi oleh ISACA (Information System Audit and Control Association). COBIT dapat membantu organisasi dalam menciptakan manfaat TI yang optimal dengan mewujudkan keseimbangan antara manfaat yang diharapkan dan mengoptimalkan tingkat resiko dan penggunaan sumber daya.

Merujuk pada permasalahan yang ada, maka dilakukanlah studi kasus untuk melakukan audit tatakelola infrastruktur TI yang dimanfaatkan pada STMIK-STIE Mikroskil berdasarkan COBIT capability model, setelah itu dilakukanlah gap analysis dari tatakelola sekarang dengan yang ditargetkan, kemudian diberikanlah rekomendasi perbaikan dan peningkatan tatakelola infrastruktur TI.

Evaluasi tatakelola yang dilakukan pada infrastruktur TI akan memberikan masukan, kesadaran bagi bagian yang terkait, serta membantu manajemen dalam pengadaan sumber daya TI dan menambah pengetahuan dalam penggunaan COBIT 5 sebagai kerangka kerja untuk proses evaluasi tatakelola infrastruktur TI.

\section{RUANG LINGKUP}

Dalam penelitian ini permasalahan mencakup:

1. Penelitian dilakukan untuk mempelajari identifikasi proses tatakelola infrastruktur TI berdasarkan prinsipprinsip COBIT 5.

2. Objek penelitian dilakukan pada tatakelola infrastruktur TI di STMIK-STIE MIKROSKIL di Medan.

3. Metode pengukuran yang dipergunakan adalah dengan wawancara, kuesioner, pengecekan dokumen terkait, observasi dan real performance untuk kemudian dipilih proses-proses tatakelola yang digunakan untuk melakukan pengukuran.

4. Proses yang dibahas berdasarkan pemetaan COBIT 5 Process terhadap IT-related Goal pada STMIK XYZ adalah:
1) EDM01 (Ensure Governance Framework Setting and Maintenance)
2) EDM02 (Ensure Benefit Delivery)
3) EDM04 (Ensure Resources Optimisation)
4) APO01 (Manage The IT Management Framework)
5) APO03 (Manage Enterprise Architecture)
6) APO04 (Manage Innovation)
7) APO07 (Manage Human Resources)
8) BAI02 (Manage Requirements Definition)
9) DSS05 (Manage Security Service)
10) MEA01 (Monitor, Evaluate and Assess Performance and Comformance)

\section{BAHAN DAN METODE}

COBIT 5 akan digunakan sebagai dasar untuk melakukan penelitian ini. Metode yang akan digunakan meliputi wawancara, kuesioner, pemeriksaan dokumen, observasi dan real performance.

\subsection{COBIT 5}

COBIT (Control Objectives for Information and Related Technology) disusun oleh Information Systems Audit and Control Foundation (ISACA) pada tahun 1996. Edisi kedua dari COBIT diterbitkan pada tahun 1998. Pada tahun 2000 dirilis COBIT 3.0 oleh ITGI (Information Technology Governance Institute) dan COBIT 4.0 pada tahun 2005. COBIT 4.1 dirilis pada tahun 2007. Rilis berikutnya COBIT 5 pada tahun 2012 yang merupakan lanjutan dari COBIT 4.1; yang sudah merupakan integrasi dengan framework, standar, dan sumber daya lainnya yang terkait dengan International Organization for Standarization (ISO).

COBIT didasari oleh analisis dan harmonisasi dari standar teknologi informasi dan best practices yang ada, serta sesuai dengan prinsip governance yang diterima secara umum. COBIT berada pada level atas, yang dikendalikan oleh kebutuhan bisnis, yang mencakupi seluruh aktivitas teknologi informasi, dan mengutamakan apa yang seharusnya dicapai dari pada bagaimana untuk mencapai tatakelola, manajemen dan kontrol yang efektif.

COBIT menyediakan solusi untuk tatakelola teknologi informasi melalui domain, proses, tujuan, kegiatan, model kematangan dan struktur yang logis dan teratur. Kerangka ini dapat membantu optimalisasi investasi yang berkaitan dengan teknologi informasi, menjamin penyampaian layanan dan memberikan alat ukur atau standar yang efektif untuk kepentingan manajemen.

Tujuan utama COBIT adalah memberikan kebijaksanaan yang jelas dan latihan yang bagus bagi IT Governance bagi organisasi di seluruh dunia untuk membantu manajemen senior untuk memahami dan mengatur resiko-resiko yang berhubungan dengan TI. COBIT melakukannya dengan menyediakan kerangka kerja IT Governance dan petunjuk kontrol objektif yang rinci bagi manajemen, pemilik proses bisnis, pemakai dan auditor (ISACA, 2012).

\subsection{Metode}

Metode analisis yang digunakan dalam studi kasusu ini mengacu pada kerangka kerja COBIT 5. Adapun metode yang dilakukan menggunakan teknik wawancara dan kuesioner, pengecekan dokumen terkait, observasi dan real performance untuk menilai tingkat kapabilitas dengan process capability model.

Langkah-langkah penyelesaian masalah diharapkan mampu menggali informasi yang terkait dengan permasalahan yang akan diteliti dan objek yang menjadi tujuan penelitian dan menjadi awal pemikiran dalam melaksanakan kegiatan penelitian.

1. Identifikasi permasalahan dan potensi

Melakukan kajian terhadap permasalahan dan menganalisis potensi yang dapat diperoleh dengan mempelajari gambaran umum organisasi, menentukan ruang lingkup identifikasi dengan berdiskusi bersama tim Pusat Sistem Informasi dari STMIK-STIE Mikroskil berdasarkan standar COBIT 5 dan membuat rencana evaluasi di masa mendatang. 
2. Studi literatur

Mencari dasar-dasar teori dan penemuan dari penelitian yang telah dilakukan sebelumnya. Teori diperoleh dari website resmi ISACA, jurnal dan publikasi jurnal nasional dan internasional dengan fokus pada identifikasi proses tatakelola infrastruktur TI dengan memanfaatkan kerangka prinsip COBIT 5.

3. Pengumpulan data, wawancara dan laporan terkait Pengumpulan data, wawancara dan mempelajari dokumen-dokumen terkait dilakukan dengan meneliti SOP, rencana kerja, kebijakan-kebijakan dan hasil audit sebelumnya. Guided interview digunakan untuk mendapatkan informasi dan meyakinkan responden terhadap jawaban yang mereka pilih.

4. Audit infrastruktur TI dengan Process Capability Model

Mengevaluasi perkembangan kondisi infrastruktur TI yang digunakan saat ini dengan melakukan penelitian deskriptif yang dimana hasil penelitian disajikan dalam bentuk deskripsi. Pengukuran dilakukan dengan menggunakan model kapabilitas tatakelola infrastruktur TI yang ada di STMIK-STIE Mikroskil saat ini dengan didasari kerangka kerja COBIT 5. Data yang digunakan terdiri dari data primer dan data sekunder. Data primer dapat diperoleh dengan wawancara, kuesioner, survey, dan observasi pada tatakelola infrastruktur teknologi informasi. Data sekunder diperoleh dengan mempelajari laporan dan publikasi yang relevan dengan studi kasus ini. Kuesioner yang digunakan berisi pertanyaan-pertanyaan yang sesuai dengan subdomain COBIT 5 yaitu EDM01, EDM02, EDM04, APO01, APO03, APO04, APO07, BAI02, DSS05, dan MEA01 yang diperoleh dari hasil pemetaan IT-related goals dan process goals dengan jawaban penyataan Ya bernilai 1 dan Tidak bernilai 0 .

5. Analisis kesenjangan

Analisis kesenjangan mengacu pada kegiatan mengamati infrastruktur TI yang ada sekarang dengan yang ditargetkan kemudian dipetakan untuk mengetahui tingkat kesenjangan dalam tatakelola infrastruktur TI.

6. Rekomendasi

Hasil yang diperoleh akan dimanfaatkan untuk pemberian rekomendasi sehingga dapat disesuaikan dengan pencapaian level yang ada dalam Process Assessment Model.

7. Kesimpulan dan saran

Menganalisa perbedaan level kapabilitas proses STMIK-STIE Mikroskil dengan target yang telah ditentukan serta memberikan rekomendasi dan saran untuk menaikkan level kapabilitas proses agar mencapai target yang diharapkan.

\subsection{Responden}

Responden yang akan menerima kuesioner adalah sebanyak 50 orang dengan mengacu pada tabel RACI (Responsible, Accountable, Consulted and Informed). DI mana pemilihan responden disesuaikan dengan apa, dan kepada siapa harus didelegasikan proses terkait (ISACA, 2012).

RACI memiliki 4 aspek yang perlu diperhatikan yakni $\mathrm{R}$ adalah Responsible artinya pihak yang harus memastikan aktifitas tersebut berhasil dilaksanakan. A adalah Accountable yang memiliki arti pihak yang harus memastikan aktivitas tersebut berhasil dilaksanakan. C adalah Consulted yang memiliki arti pihak yang mana pendapatnya dibutuhkan dalam aktifitas. I adalah Informed yang artinya pihak yang selalu menjaga kemajuan informasi atas aktifitas yang dilakukan.

\subsection{Kerangka Pikir}

Urutan langkah-langkah penelitian penyelesaian masalah dapat dilihat pada Gambar 1 di bawah ini:

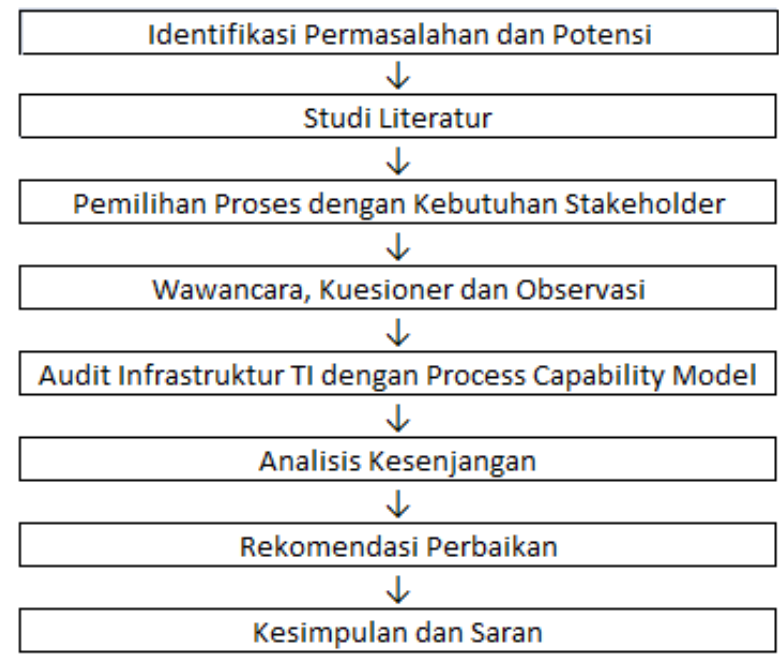

Gambar 1. Langkah-Langkah Penelitian

Kerangka penelitian di atas diharapkan mampu menggali informasi yang terkait dengan permasalahan yang akan diteliti dan objek yang menjadi tujuan penelitian. Kerangka ini memberikan dasar bagi arah penelitian yang akan dilakukan serta menjadi awal pemikiran bagi setiap peneliti sehingga penelitian yang dilakukan dapat dijadikan acuan di kemudian hari.

\subsection{Skala Pengukuran COBIT 5}

Pengukuran kemampuan proses dan peringkat skala COBIT 5 mengacu pada ISO/IEC 15504. Peringkat yang ada di dalam COBIT 5 ini adalah (ISACA, 2013):

Tabel 1. Tingkat Kapabilitas Proses

\begin{tabular}{|c|c|}
\hline Level & Pencapaian \\
\hline $\mathrm{N}:$ Not Achieved & $0 \%-15 \%$ \\
\hline $\mathrm{P}:$ Partially Achieved & $15 \%-50 \%$ \\
\hline L: Largely Achieved & $50 \%-85 \%$ \\
\hline F : Fully Achieved & $85 \%-100 \%$ \\
\hline
\end{tabular}

\subsection{Skala Governance/Management Practice dan Work Product}

Hasil isian kuesioner akan dihitung tingkat kapabilitas untuk setiap sub domain berdasarkan governance/management practice dan work product yang dihasilkan. Di mana isian $\mathrm{Y}$ bernilai 1 dan $\mathrm{T}$ bernilai 0 .

Skala governance/management practice dan work product dapat dihitung dengan rumus (Nugroho, 2013):

1. Skala governance/management practice 


\section{$\frac{2 \text { (Aktivitas Bernilai 1) }}{\text { Total Aktivitas }} \times 100 \%$}

2. Skala work product

$$
\frac{\sum(\text { Output Bernilai } 1)}{\text { Total Output }} \times 100 \%
$$

Skala \% (persentase) diperoleh dari rata-rata persentase governance/management practice(1) dan work product (2) untuk masing-masing proses berdasarkan hasil rekapitulasi kuesioner yang telah diisi.

Yang kemudian akan disesuaikan dengan tingkat kapabilitas dari setiap proses yang diperoleh berdasarkan kategori pada Tabel 1. Jika level 1 diperoleh Largely Achieved (L) atau Fully Achieved (F) maka akan disebarkan kuesioner tahap dua yang berisikan pertanyaan-pertanyaan terkait dengan pencapaian generic practice, generic resources dan generic work product yang ada dalam setiap atribut proses.

Namun untuk dapat dilanjukan kegiatan evaluasi level 2 sampai level 5 maka setiap level pada sub domain harus memiliki pencapaian Full Achieved (F).

\subsection{COBIT 5 Process Capability Model}

Ada enam level dari kemampuan yang dapat dicapai oleh sebuah proses, termasuk penunjukan proses yang tidak lengkap jika praktik di dalamnya tidak mencapai tujuan yang dimaksudkan oleh proses (ISACA, 2012). Keenam level proses tersebut adalah sebagai berikut :

0 Incomplete Process - Proses yang tidak dilaksanakan atau gagal untuk mencapai tujuan prosesnya. Pada tingkat ini, ada bukti sedikit atau tidak ada dari setiap prestasi sistematis tujuan proses.

1. Performed Process (satu atribut yaitu process performance) - Proses yang dilaksanakan mencapai tujuan prosesnya.

2. Managed Process (dua atribut yaitu performance management dan work product management) Proses dikelola dan produk kerja ditetapkan, dikendalikan dan dipelihara.

3. Established Process (dua atribut yaitu process definition dan process deployment) - Definisi proses digunakan berdasarkan standar proses

4. Predictable Process (dua atribut yaitu process measurement dan process control) - Proses berlaku secara konsisten dalam batas yang ditentukan
5. Optimising Process (dua atribut yaitu process innovation dan process optimization) - Proses terus ditingkatkan untuk memenuhi tujuan bisnis yang relevan saat ini dan proyeksi.

\subsection{Capability Model}

Hasil penilaian capability level masing-masing proses dapat dilakukan dengan rumus rata-rata sebagai berikut (Hidayat \& Rahmat, 2015) :

Capability Level $=$

$\frac{(0 * y 0)+(1 * y 1)+(2 * y 2)+\left(3 * y^{3}\right)+\left(4 * y^{4}\right)+(5 * y 5)}{z}$

Keterangan (3) :

Yn (y0...y5) : Jumlah proses yang berada di level $\mathrm{n}$

$\mathrm{Z} \quad$ : Jumlah proses yang dievaluasi

\section{PEMBAHASAN}

Identifikasi proses dilakukan untuk memfokuskan studi kasus yang akan dilakukan. Pemilihan proses mengacu pada prinsip-prinsip COBIT 5 yang merupakan salah satu enabler dalam COBIT 5 untuk membantu pencapaian tujuan organisasi.

\subsection{Prinsip Pertama: Meeting Stakeholder Needs}

Dalam memenuhi kebutuhan stakeholder, dilakukanlah proses wawancara dengan memanfaatkan pertanyaan yang terkait dengan tujuan strategi organisasi. COBIT 5 menerjemahkan kebutuhan stakeholder dalam tujuan yang spesifik, praktikal dan terkostumisasi dari tujuan organisasi, tujuan terkait TI dan tujuan enabler.

Dalam hal ini, stakeholder memerlukan governance objectives di mana optimasi sumber daya TI dibutuhkan bagian PSI untuk melakukan tatakelola TI organisasi. Optimasi sumber daya TI sejalan dengan tujuan tatakelola infrastruktur TI untuk penyampaian nilai terhadap bisnis yang didorong oleh penyelerasan strategi TI terhadap bisnis. Maka dari itu, pemilihan tujuan tatakelola diambil dari nilai primer $(\mathrm{P})$ dari optimization resource seperti yang ditunjukkan pada Gambar 2 berikut ini: 


\begin{tabular}{|c|c|c|c|c|}
\hline \multirow[b]{2}{*}{$\begin{array}{l}\text { BSC } \\
\text { DIMEIsion }\end{array}$} & \multirow[b]{2}{*}{ ENTERPRISE GOALS } & \multicolumn{3}{|c|}{ GOVERULANKE OBJECTIVES } \\
\hline & & $\begin{array}{c}\text { BENERTIS } \\
\text { REAUSATION }\end{array}$ & $\begin{array}{c}\text { RISK } \\
\text { MANAGEMENT }\end{array}$ & $\begin{array}{c}\text { RESOURCE } \\
\text { OPMMISAMON }\end{array}$ \\
\hline \multirow{5}{*}{ FINANCAL } & 1. STAKEHOLDER VALUE OF BUSINESS INVETTMENTS & $\mathbf{P}$ & & \\
\hline & 2. PORTFOUO OF COMPEITIVE PRODUCTS AND SERVIES & $\mathbf{P}$ & & 5 \\
\hline & 3. MANAGED BUSINESS RISIS (SAFEGUARDING OF ASSETS) & - & $\mathbf{P}$ & 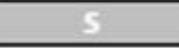 \\
\hline & 4. COMPUANCE WTH EXTERNALL LAWS AND REGULATONS & & $\mathbf{P}$ & \\
\hline & 5. FINANOAL TRARISPARENKCY & $\mathbf{P}$ & 5 & 5 \\
\hline \multirow{5}{*}{ CUSTOMER } & 6. CUSTOMER-ORIENTED SERVICE CULTURE & $\mathbf{P}$ & & 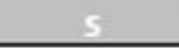 \\
\hline & 7. BUSINESS SERVICE CONTINUITY AND AVAILABIUTY & & $\mathbf{P}$ & \\
\hline & 8. AGILE RESPONLES TO A CHANGING BUSINESS ENMRONIMENT & $\mathbf{P}$ & & 5 \\
\hline & 9. INFCEMATION-BOSED STRATEGIC DECISION MAMNG & $\mathbf{P}$ & $\mathbf{P}$ & (P) \\
\hline & 10. OPTIMISATION OF SERVICE DELUVERY COSTS & $\mathbf{P}$ & & 5 \\
\hline \multirow{5}{*}{ INTERNAL } & 11. OPMIMISATION OF BUSINESS PROCESS FUNICTIONALUTY & $\mathbf{P}$ & & (P) \\
\hline & 12. OPTIMISATION OF BUSINESS PROCESS COSTS & $\mathbf{P}$ & & (P) \\
\hline & 13. MANAGED BUSINESS CHANGE PROGRAMMMES & $\mathbf{P}$ & $\mathbf{P}$ & 5 \\
\hline & 14. OPERATONAL ANND STAFF PROOUCTIMTY & $\mathbf{P}$ & & (P) \\
\hline & 15. COMPUANCE WTH INTERANAL POUCIES & & $\mathbf{P}$ & \\
\hline \multirow{2}{*}{$\begin{array}{l}\text { LEARNING } \\
\text { AND } \\
\text { GROWTH }\end{array}$} & 16. SKIUED AND MOTIVATED PEOPLE & $\bar{s}$ & $\bar{s}$ & (P) \\
\hline & 17. Product AND BUsiness innovation CUItURE & $\mathbf{P}$ & & \\
\hline
\end{tabular}

Gambar 2. Enterprise Goals Mapped to Governance Objectives

COBIT 5 mendefinisikan 17 tujuan generik yang berisi daftar tujuan organisasi dan bagaimana tujuan organisasi berhubungan dengan tujuan tatakelola. Hubungan primer dari tujuan tatakelola optimalisasi sumber daya yang terlihat pada Gambar 2 di atas adalah sebagai berikut:

1. Information-based strategic decision making (9)

2. Optimization of business process functionality (11)

3. Optimization of business process costs (12)

4. Operational and staff productivity (14)

5. Skilled and motivated people (16)

Kelima tujuan organisasi yang diperoleh memerlukan sejumlah hasil yang berkaitan dengan TI. Pemetaan enterprise goals ke IT-related goals dapat dilihat pada Gambar 3 di bawah ini:

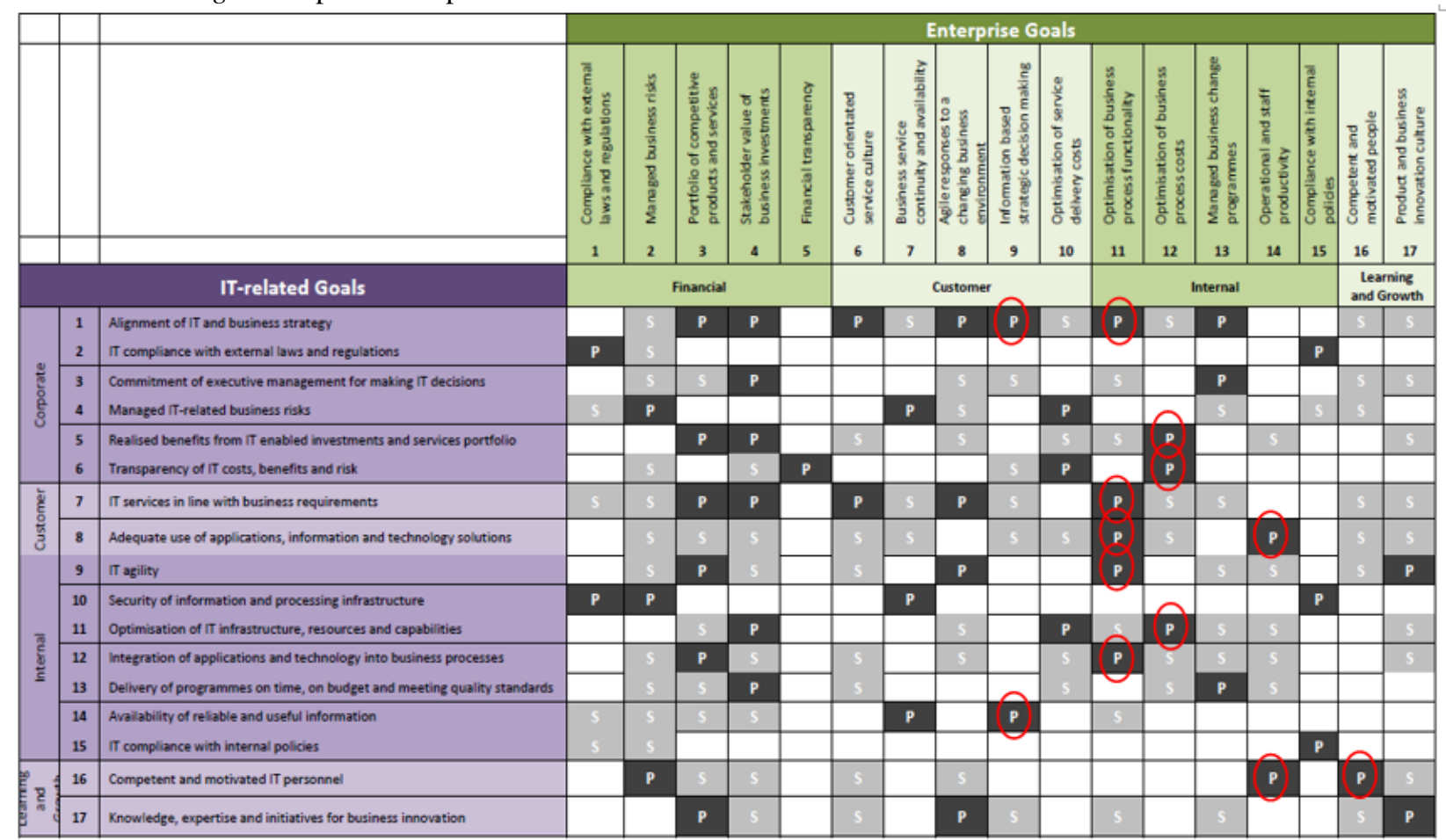

Gambar 3. Enterprise Goals Mapped to IT-related Goals

Hasil pemetaan memperlihatkan bahwa tujuan organisasi yang terhubung dengan tujuan terkait TI pada Gambar 3 dapat diambil dari hubungan primer antara kedua tujuan yang ada sebagai berikut: 
1. Alignment of IT and business strategy (1)

2. Realised benefits from IT enabled investments and services portofolio (5)

3. Transparency of IT costs, benefits and risk (6)

4. IT services in line with business requirements (7)

5. Adequate use of applications, information and technology solutions (8)

6. IT agility (9)

7. Optimization of IT infrastructure, resources and capabilities (11)

8. Integration of applications and technology into business processes (12)

9. Availability of reliable and useful information (14)

10. Competent and motivated IT personnel (16)

Tujuan yang berhubungan dengan TI memerlukan keberhasilan tatakelola dan penggunaan sejumlah pengaktif yang akan dicapai. Pengaktif mencakup proses, staruktur organisasi dan informasi yang nantinya didefinisikan untuk mendukung tujuan terkait dengan TI. Setelah mendiskusikan dengan Ketua PSI maka dari 37 proses COBIT 5 yang ada serta hubungan primer dan sekunder antara proses-proses COBIT 5 dan tujuan terkait TI, diambillah 10 proses yang memenuhi kegiatan identifikasi proses terkait TI dan tujuan terkait TI dalam STMIK-STIE Mikroskil seperti yang terlihat dalam Gambar 4 di bawah ini. Dari pemetaan yang dilakukan maka diperoleh gambaran dari pemilihan proses yang terdapat dalam COBIT 5 antara lain: EDM01, EDM02, EDM04, APO01, APO03, APO04, APO07, BAI02, DSS05, MEA01.

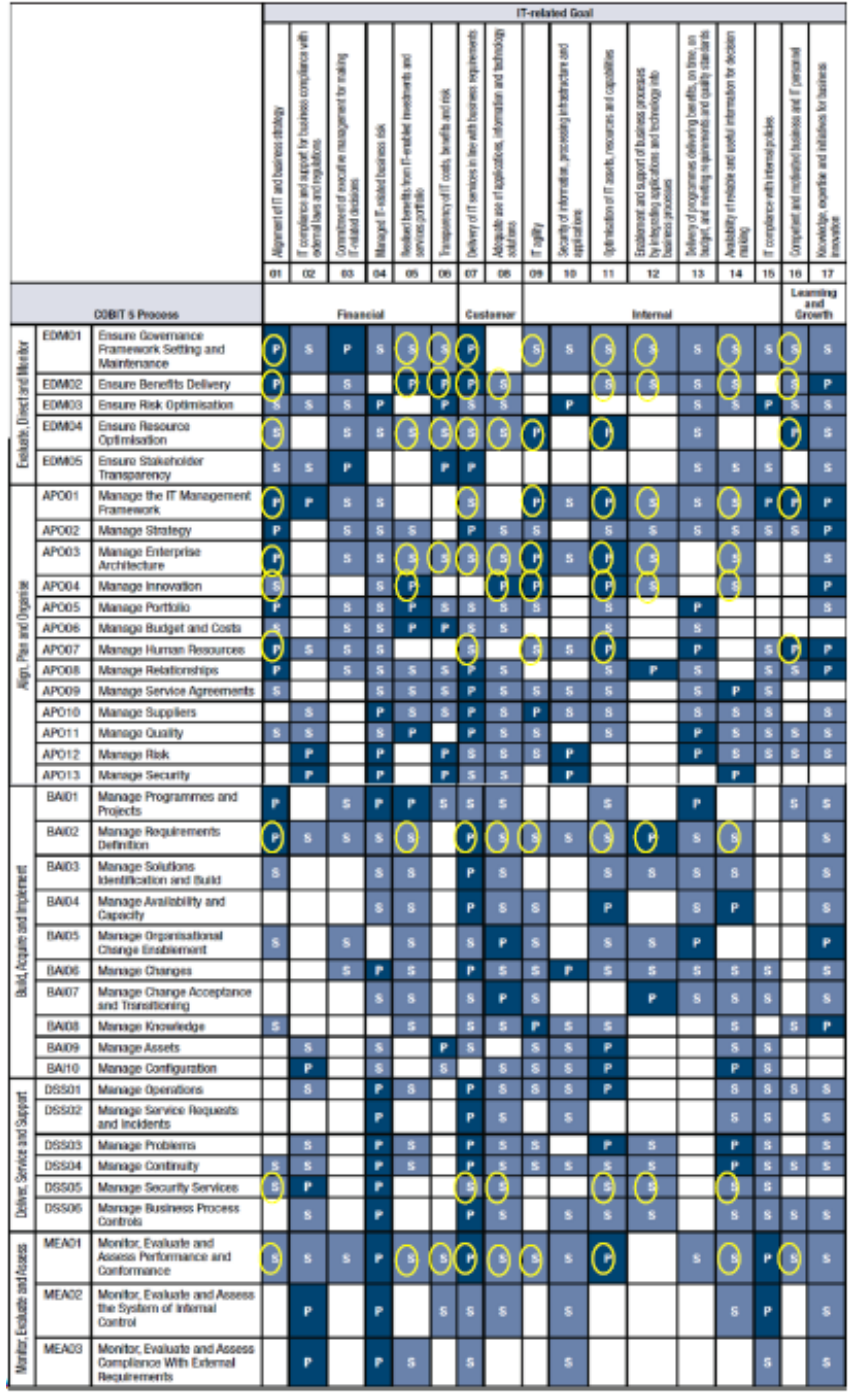

Gambar 4. IT-related Goals Mapped to Process Goals (ISACA, 2011)

\subsection{Prinsip Kedua: Covering The Enterprise End to End}

Dalam prinsip kedua ini, peneliti melakukan analisis pada aspek atau peristiwa penting dalam kegiatan tatakelola organisasi. Salah satunya dengan melakukan analisis pada struktur organisasi untuk mempelajari pemilik dan stakeholder, badan tatakelola, manajemen dan juga bagian operasional STMIK-STIE Mikroskil.

\subsection{Prinsip Ketiga: Applying A Single, Integrated Framework}

Kerangka kerja yang digunakan oleh peneliti adalah COBIT 5 di mana terdapat panduan yang dikeluarkan oleh ISACA dalam situsnya. Dalam COBIT 5 juga diselaraskan dengan standar lain seperti ISO 15504 yang disesuaikan dengan model PAM (Process Accessment Model) dalam kegiatan evaluasi dan audit lanjutan.

\subsection{Prinsip Keempat: Enabling A Holistic Approach}

Peneliti mengkategorikan enabler dalam beberapa bagian seperti:

1. Principles, Policies and Frameworks

2. Processes 
3. Organisational Structures

4. Culture, Ethics and Behaviour

5. Information

6. Services, Infrastructure and Applications

7. People, Skills, and Competencies

\subsection{Prinsip Kelima: Separating Governance From Management}

Dari hasil pemetaan yang telah dilakukan, diperoleh 10 proses-proses COBIT 5 yang dapat digunakan untuk melakukan kegiatan evaluasi tatakelola infrastruktur TI di masa mendatang. Untuk proses tatakelola menggunakan EDM01, EDM02, EDM04. Untuk proses manajemen menggunakan APO01, APO03, APO04, APO07, BAI02, DSS05 dan MEA01.

\subsection{Pencapaian Level pada Proses COBIT}

Hasil pencapaian level yang didapatkan setelah perhitungan 10 proses COBIT dapat dipetakan sebagai berikut :

1. Pencapaian EDM01

Proses EDM01 mencapai level 3 namun tidak dapat dilanjutkan ke level 4 dikarenakan nilai pencapaian hanya berada pada Largely Achieved (L) sebesar 60\% pada PA 3.1 dan $67 \%$ pada PA 3.2. Hasil pencapaian dapat dilihat pada Tabel 2 .

\section{Tabel 2. Pencapaian EDM01}

\begin{tabular}{|l|c|c|c|c|c|c|c|c|c|c|}
\hline $\begin{array}{l}\text { Nama } \\
\text { Proses }\end{array}$ & $\begin{array}{l}\text { Level } \\
0\end{array}$ & \multicolumn{2}{l|l|}{$\begin{array}{l}\text { Level } \\
1\end{array}$} & \multicolumn{2}{|l|}{ Level 2 } & \multicolumn{2}{l|}{ Level 3 } & \multicolumn{2}{l|}{ Level 4 } & \multicolumn{2}{l|}{ Level 5 } \\
\hline EDM01 & & $\begin{array}{l}\text { PA } \\
1.1\end{array}$ & $\begin{array}{l}\text { PA } \\
2.1\end{array}$ & $\begin{array}{l}\text { PA } \\
2.2\end{array}$ & $\begin{array}{l}\text { PA } \\
3.1\end{array}$ & $\begin{array}{l}\text { PA } \\
3.2\end{array}$ & $\begin{array}{l}\text { PA } \\
4.1\end{array}$ & $\begin{array}{l}\text { PA } \\
4.2\end{array}$ & $\begin{array}{l}\text { PA } \\
5.1\end{array}$ & $\begin{array}{l}\text { PA } \\
5.2\end{array}$ \\
\hline $\begin{array}{l}\text { Rating } \\
\text { berdasarkan } \\
\text { persentase }\end{array}$ & $100 \%$ & $94 \%$ & $100 \%$ & $100 \%$ & $60 \%$ & $67 \%$ & & & & \\
\hline $\begin{array}{l}\text { Level } \\
\text { kapabilitas } \\
\text { yang } \\
\text { dicapai }\end{array}$ & F & F & F & F & L & L & & & & \\
\hline
\end{tabular}

\section{Pencapaian EDM02}

Proses EDM02 mancapai level 1 dan tidak dapat diteruskan ke level 2 dikarenakan nilai pencapaian hanya berada pada Largely Achieved (L) sebesar 62\%. Hasil pencapaian dapat dilihat pada Tabel 3.

\section{Tabel 3. Pencapaian EDM02}

\begin{tabular}{|l|c|c|c|c|c|l|l|l|l|l|}
\hline $\begin{array}{l}\text { Nama } \\
\text { Proses }\end{array}$ & $\begin{array}{l}\text { Level } \\
0\end{array}$ & \multicolumn{2}{l|l}{$\begin{array}{l}\text { Level } \\
1\end{array}$} & \multicolumn{2}{|l|}{ Level 2 } & \multicolumn{2}{l|}{ Level 3 } & \multicolumn{2}{l|}{ Level 4 } & \multicolumn{2}{l|}{ Level 5 } \\
\hline EDM02 & & PA & PA & PA & PA & PA & PA & PA & PA & PA \\
1.1 & 2.1 & 2.2 & 3.1 & 3.2 & 4.1 & 4.2 & 5.1 & 5.2 \\
\hline $\begin{array}{l}\text { Rating } \\
\text { berdasarkan } \\
\text { persentase }\end{array}$ & $100 \%$ & $62 \%$ & & & & & & & & \\
\hline $\begin{array}{l}\text { Level } \\
\text { kapabilitas } \\
\text { yang } \\
\text { dicapai }\end{array}$ & F & L & & & & & & & & \\
\hline
\end{tabular}

\section{Pencapaian EDM04}

Proses EDM04 mencapai level 1 namun tidak dapat diteruskan ke level 2 karena nilai pencapaian hanya berada pada Largely Achieved (L) sebesar $81 \%$. Hasil pencapaian dapat dilihat pada Tabel 4 .
Tabel 4. Pencapaian EDM04

\begin{tabular}{|l|l|l|l|l|l|l|l|l|l|l|}
\hline $\begin{array}{l}\text { Nama } \\
\text { Proses }\end{array}$ & $\begin{array}{l}\text { Level } \\
0\end{array}$ & $\begin{array}{l}\text { Level } \\
1\end{array}$ & \multicolumn{2}{|l|}{ Level 2 } & \multicolumn{2}{l|}{ Level 3 } & \multicolumn{2}{l|}{ Level 4 } & \multicolumn{2}{l|}{ Level 5 } \\
\hline EDM04 & & $\begin{array}{l}\text { PA } \\
1.1\end{array}$ & $\begin{array}{l}\text { PA } \\
2.1\end{array}$ & $\begin{array}{l}\text { PA } \\
2.2\end{array}$ & $\begin{array}{l}\text { PA } \\
3.1\end{array}$ & $\begin{array}{l}\text { PA } \\
3.2\end{array}$ & $\begin{array}{l}\text { PA } \\
4.1\end{array}$ & $\begin{array}{l}\text { PA } \\
4.2\end{array}$ & $\begin{array}{l}\text { PA } \\
5.1\end{array}$ & $\begin{array}{l}\text { PA } \\
5.2\end{array}$ \\
\hline $\begin{array}{l}\text { Rating } \\
\text { berdasarkan } \\
\text { persentase }\end{array}$ & $100 \%$ & $81 \%$ & & & & & & & & \\
\hline $\begin{array}{l}\text { Level } \\
\text { kapabilitas } \\
\text { yang } \\
\text { dicapai }\end{array}$ & F & L & & & & & & & & \\
\hline
\end{tabular}

\section{Pencapaian APO01}

Proses APO01 mencapai level 3 namun tidak dapat diteruskan ke level 4 karena nilai pencapaian hanya berada pada Largely Achieved (L) sebesar $60 \%$ untuk PA 3.1 dan $83 \%$ untuk PA 3.2. Hasil pencapaian dapat dilihat pada Tabel 5 .

Tabel 5. Pencapaian APO01

\begin{tabular}{|l|c|c|c|c|c|c|c|l|l|l|}
\hline $\begin{array}{l}\text { Nama } \\
\text { Proses }\end{array}$ & $\begin{array}{l}\text { Level } \\
0\end{array}$ & $\begin{array}{l}\text { Level } \\
1\end{array}$ & \multicolumn{2}{l|}{ Leve1 2 } & \multicolumn{2}{l|}{ Level 3 } & \multicolumn{2}{l|}{ Level 4 } & \multicolumn{2}{l|}{ Level 5 } \\
\hline APO01 & & $\begin{array}{l}\text { PA } \\
1.1\end{array}$ & $\begin{array}{l}\text { PA } \\
2.1\end{array}$ & $\begin{array}{l}\text { PA } \\
2.2\end{array}$ & $\begin{array}{l}\text { PA } \\
3.1\end{array}$ & $\begin{array}{l}\text { PA } \\
3.2\end{array}$ & $\begin{array}{l}\text { PA } \\
4.1\end{array}$ & $\begin{array}{l}\text { PA } \\
4.2\end{array}$ & $\begin{array}{l}\text { PA } \\
5.1\end{array}$ & $\begin{array}{l}\text { PA } \\
5.2\end{array}$ \\
\hline $\begin{array}{l}\text { Rating } \\
\text { berdasarkan } \\
\text { persentase }\end{array}$ & $100 \%$ & $85 \%$ & $100 \%$ & $100 \%$ & $60 \%$ & $83 \%$ & & & & \\
\hline $\begin{array}{l}\text { Level } \\
\text { kapabilitas } \\
\text { yang } \\
\text { dicapai }\end{array}$ & F & F & F & F & L & L & & & & \\
\hline
\end{tabular}

\section{Pencapaian APO03}

Proses APO03 mencapai level 3 namun tidak dapat dilanjutkan ke level 4 karena nilai pencapaian hanya berada pada Largely Achieved (L) sebesar $60 \%$ pada PA 3.1 dan $67 \%$ pada PA3.2. Hasil pencapaian dapat dilihat pada Tabel 6 .

Tabel 6. Pencapaian APO03

\begin{tabular}{|l|c|c|c|c|c|c|l|l|l|l|}
\hline $\begin{array}{l}\text { Nama } \\
\text { Proses }\end{array}$ & $\begin{array}{l}\text { Level } \\
0\end{array}$ & $\begin{array}{l}\text { Level } \\
1\end{array}$ & \multicolumn{2}{|l|}{ Level 2 } & \multicolumn{2}{l|}{ Level 3 } & \multicolumn{2}{l|}{ Level 4 } & \multicolumn{2}{l|}{ Level 5 } \\
\hline APO03 & & $\begin{array}{l}\text { PA } \\
1.1\end{array}$ & $\begin{array}{l}\text { PA } \\
2.1\end{array}$ & $\begin{array}{l}\text { PA } \\
2.2\end{array}$ & $\begin{array}{l}\text { PA } \\
3.1\end{array}$ & $\begin{array}{l}\text { PA } \\
3.2\end{array}$ & $\begin{array}{l}\text { PA } \\
4.1\end{array}$ & $\begin{array}{l}\text { PA } \\
4.2\end{array}$ & $\begin{array}{l}\text { PA } \\
5.1\end{array}$ & $\begin{array}{l}\text { PA } \\
5.2\end{array}$ \\
\hline $\begin{array}{l}\text { Rating } \\
\text { berdasarkan } \\
\text { persentase }\end{array}$ & $100 \%$ & $92 \%$ & $100 \%$ & $100 \%$ & $60 \%$ & $67 \%$ & & & & \\
\hline $\begin{array}{l}\text { Level } \\
\text { kapabilitas } \\
\text { yang } \\
\text { dicapai }\end{array}$ & F & F & F & F & L & L & & & & \\
\hline
\end{tabular}

\section{Pencapaian APO04}

Proses APO04 mencapai level 1 namun tidak dapat dilanjutkan ke level 2 karena nilai pencapaian hanya berada pada Largely Achieved (L) sebesar 70\%. Hasil pencapaian dapat dilihat pada Tabel 7 .

Tabel 7 . Pencapaian APO04

\begin{tabular}{|l|c|l|l|l|l|l|l|l|l|l|}
\hline $\begin{array}{l}\text { Nama } \\
\text { Proses }\end{array}$ & $\begin{array}{l}\text { Level } \\
0\end{array}$ & $\begin{array}{l}\text { Level } \\
1\end{array}$ & \multicolumn{2}{l|}{ Level 2 } & \multicolumn{2}{l|}{ Level 3 } & \multicolumn{2}{l|}{ Level 4 } & \multicolumn{2}{l|}{ Level 5 } \\
\hline APO04 & & $\begin{array}{l}\text { PA } \\
1.1\end{array}$ & $\begin{array}{l}\text { PA } \\
2.1\end{array}$ & $\begin{array}{l}\text { PA } \\
2.2\end{array}$ & $\begin{array}{l}\text { PA } \\
3.1\end{array}$ & $\begin{array}{l}\text { PA } \\
3.2\end{array}$ & $\begin{array}{l}\text { PA } \\
4.1\end{array}$ & $\begin{array}{l}\text { PA } \\
4.2\end{array}$ & $\begin{array}{l}\text { PA } \\
5.1\end{array}$ & $\begin{array}{l}\text { PA } \\
5.2\end{array}$ \\
\hline $\begin{array}{l}\text { Rating } \\
\text { berdasarkan } \\
\text { persentase }\end{array}$ & $100 \%$ & $70 \%$ & & & & & & & & \\
\hline $\begin{array}{l}\text { Level } \\
\text { kapabilitas } \\
\text { yang } \\
\text { dicapai }\end{array}$ & F & L & & & & & & & & \\
\hline
\end{tabular}

\section{Pencapaian APO07}

Proses APO07 mencapai level 3 dan dapat dilanjuutkan ke level 4 namun setelah dipertanyakan 
kuesioner tahap dua ke pihak terkait diperoleh nilai kapabilitas sebesar $0 \%$ yang berarti pencapaian penuh untuk prosess measurement (PA 4.1) dan juga prosess control (PA 4.2) belum dilakukan oleh pihak Mikroskil terkait dengan pengelolaan sumber daya manusia. Hasil pencapaian dapat dilihat pada Tabel 8.

Tabel 8. Pencapaian APO07

\begin{tabular}{|l|c|c|c|c|l|l|l|l|l|l|}
\hline $\begin{array}{l}\text { Nama } \\
\text { Proses }\end{array}$ & $\begin{array}{l}\text { Level } \\
0\end{array}$ & $\begin{array}{l}\text { Level } \\
1\end{array}$ & \multicolumn{2}{l|l|}{ Level 2 } & \multicolumn{2}{l|}{ Level 3 } & \multicolumn{2}{l|}{ Level 4 } & \multicolumn{2}{l|}{ Level 5 } \\
\hline APO07 & & $\begin{array}{l}\text { PA } \\
1.1\end{array}$ & $\begin{array}{l}\text { PA } \\
2.1\end{array}$ & $\begin{array}{l}\text { PA } \\
2.2\end{array}$ & $\begin{array}{l}\text { PA } \\
3.1\end{array}$ & $\begin{array}{l}\text { PA } \\
3.2\end{array}$ & $\begin{array}{l}\text { PA } \\
4.1\end{array}$ & $\begin{array}{l}\text { PA } \\
4.2\end{array}$ & $\begin{array}{l}\text { PA } \\
5.1\end{array}$ & $\begin{array}{l}\text { PA } \\
5.2\end{array}$ \\
\hline $\begin{array}{l}\text { Rating } \\
\text { berdasarkan } \\
\text { persentase }\end{array}$ & $100 \%$ & $89 \%$ & $100 \%$ & $100 \%$ & $100 \%$ & $100 \%$ & $0 \%$ & $0 \%$ & & \\
\hline $\begin{array}{l}\text { Level } \\
\text { kapabilitas } \\
\text { yang } \\
\text { dicapai }\end{array}$ & F & F & F & F & F & F & N & N & & \\
\hline
\end{tabular}

\section{Pencapaian BAI02}

Proses BAI02 mencapai level 1 namun tidak dapat dilanjutkan ke level 2 karena nilai pencapaian hanya berada pada Largely Achieved (L) sebesar 62\%. Hasil pencapaian dapat dilihat pada Tabel 9.

\section{Tabel 9. Pencapaian BAI02}

\begin{tabular}{|l|c|l|l|l|l|l|l|l|l|l|}
\hline $\begin{array}{l}\text { Nama } \\
\text { Proses }\end{array}$ & $\begin{array}{l}\text { Level } \\
0\end{array}$ & \multicolumn{2}{l|l|}{$\begin{array}{l}\text { Level } \\
1\end{array}$} & \multicolumn{2}{|l|}{ Level 2 } & \multicolumn{2}{l|}{ Level 3 } & \multicolumn{2}{l|}{ Level 4 } & \multicolumn{2}{l|}{ Level 5 } \\
\hline BAI02 & & $\begin{array}{l}\text { PA } \\
1.1\end{array}$ & $\begin{array}{l}\text { PA } \\
2.1\end{array}$ & $\begin{array}{l}\text { PA } \\
2.2\end{array}$ & $\begin{array}{l}\text { PA } \\
3.1\end{array}$ & $\begin{array}{l}\text { PA } \\
3.2\end{array}$ & $\begin{array}{l}\text { PA } \\
4.1\end{array}$ & $\begin{array}{l}\text { PA } \\
4.2\end{array}$ & $\begin{array}{l}\text { PA } \\
5.1\end{array}$ & $\begin{array}{l}\text { PA } \\
5.2\end{array}$ \\
\hline $\begin{array}{l}\text { Rating } \\
\text { berdasarkan } \\
\text { persentase }\end{array}$ & $100 \%$ & $62 \%$ & & & & & & & & \\
\hline $\begin{array}{l}\text { Level } \\
\text { kapabilitas } \\
\text { yang } \\
\text { dicapai }\end{array}$ & F & L & & & & & & & & \\
\hline
\end{tabular}

\section{Pencapaian DSS05}

Proses DSS05 mencapai level 4 dan dapat diteruskan ke level 5 namun pencapaian PA 5.2 (Process Optimisation) tidak dapat dipenuhi karena nilai pencapaian berada pada Partially Achieved (P) sebesar $33 \%$ yang berarti process optimization belum terlaksana dan kegiatan evaluasi belum dapat dioptimalkan. Hasil pencapaian dapat dilihat pada Tabel 10 .

\section{Tabel 10. Pencapaian DSS05}

\begin{tabular}{|c|c|c|c|c|c|c|c|c|c|c|}
\hline \multirow{2}{*}{$\begin{array}{l}\text { Nama } \\
\text { Proses } \\
\text { DSS05 }\end{array}$} & \multirow{2}{*}{$\begin{array}{l}\text { Level } \\
0\end{array}$} & \multirow{2}{*}{$\begin{array}{l}\text { Level } \\
1 \\
\text { PA } \\
1.1\end{array}$} & \multicolumn{2}{|c|}{ Level 2} & \multicolumn{2}{|c|}{ Level 3} & \multicolumn{2}{|c|}{ Level 4} & \multicolumn{2}{|c|}{ Level 5} \\
\hline & & & $\begin{array}{l}\text { PA } \\
2.1\end{array}$ & $\begin{array}{l}\text { PA } \\
2.2\end{array}$ & $\begin{array}{l}\text { PA } \\
3.1\end{array}$ & $\begin{array}{l}\text { PA } \\
3.2\end{array}$ & $\begin{array}{l}\mathrm{PA} \\
4.1\end{array}$ & $\begin{array}{l}\text { PA } \\
4.2\end{array}$ & $\begin{array}{l}\text { PA } \\
5.1\end{array}$ & $\begin{array}{l}\text { PA } \\
5.2\end{array}$ \\
\hline $\begin{array}{l}\text { Rating } \\
\text { berdasarkan } \\
\text { persentase }\end{array}$ & $100 \%$ & $90 \%$ & $100 \%$ & $100 \%$ & $100 \%$ & $100 \%$ & $100 \%$ & $100 \%$ & $100 \%$ & $33 \%$ \\
\hline $\begin{array}{l}\text { Level } \\
\text { kapabilitas } \\
\text { yang } \\
\text { dicapai }\end{array}$ & $\mathrm{F}$ & $\mathrm{F}$ & $\mathrm{F}$ & $\mathrm{F}$ & $\mathrm{F}$ & $\mathrm{F}$ & $\mathrm{F}$ & $\mathrm{F}$ & $\mathrm{F}$ & $\mathbf{P}$ \\
\hline
\end{tabular}

\section{Pencapaian MEA01}

Proses MEA01 mencapai level 1 namun belum dapat diteruskan ke level 2 karena nilai pencapaian hanya berada pada Largely Achieved (L) sebesar 67\%. Hasil pencapaian dapat dilihat pada Tabel 11 .
Tabel 11. Pencapaian MEA01

\begin{tabular}{|l|c|c|c|l|l|l|l|l|l|l|}
\hline $\begin{array}{l}\text { Nama } \\
\text { Proses }\end{array}$ & $\begin{array}{l}\text { Level } \\
0\end{array}$ & $\begin{array}{l}\text { Level } \\
1\end{array}$ & \multicolumn{2}{l|}{ Level 2 } & \multicolumn{2}{l|}{ Level 3 } & \multicolumn{2}{l|}{ Level 4 } & \multicolumn{2}{l|}{ Level 5 } \\
\hline MEA01 & & $\begin{array}{l}\text { PA } \\
1.1\end{array}$ & $\begin{array}{l}\text { PA } \\
2.1\end{array}$ & $\begin{array}{l}\text { PA } \\
2.2\end{array}$ & $\begin{array}{l}\text { PA } \\
3.1\end{array}$ & $\begin{array}{l}\text { PA } \\
3.2\end{array}$ & $\begin{array}{l}\text { PA } \\
4.1\end{array}$ & $\begin{array}{l}\text { PA } \\
4.2\end{array}$ & $\begin{array}{l}\text { PA } \\
5.1\end{array}$ & $\begin{array}{l}\text { PA } \\
5.2\end{array}$ \\
\hline $\begin{array}{l}\text { Rating } \\
\text { berdasarkan } \\
\text { persentase }\end{array}$ & $100 \%$ & $67 \%$ & & & & & & & & \\
\hline $\begin{array}{l}\text { Level } \\
\text { kapabilitas } \\
\text { yang } \\
\text { dicapai }\end{array}$ & F & L & & & & & & & & \\
\hline
\end{tabular}

\subsection{Analisis Kesenjangan}

Hasil analisis tingkat kapabilitas saat ini (as-is) dan target tingkat kapabilitas yang diharapkan (to-be) terhadap kesenjangan pada setiap prosesnya. Analisis kesenjangan dapat dilihat pada Tabel 12 dan Grafik Kesenjangan pada Gambar 5. di bawah ini.

Tabel 12. Analisis Kesenjangan

\begin{tabular}{|c|l|c|c|c|}
\hline \multirow{2}{*}{ No. } & \multirow{2}{*}{ Proses } & \multicolumn{3}{|c|}{ Analisa Gap } \\
\cline { 3 - 5 } & & as-is & to-be & Gap \\
\hline 1 & EDM01 & 3 & 4 & 1 \\
\hline 2 & EDM02 & 1 & 4 & 3 \\
\hline 3 & EDM04 & 1 & 4 & 3 \\
\hline 4 & APO01 & 3 & 4 & 1 \\
\hline 5 & APO03 & 3 & 4 & 1 \\
\hline 6 & APO04 & 1 & 4 & 3 \\
\hline 7 & APO07 & 3 & 4 & 1 \\
\hline 8 & BAI02 & 1 & 4 & 3 \\
\hline 9 & DSS05 & 4 & 4 & 0 \\
\hline 10 & MEA01 & 1 & 4 & 3 \\
\hline
\end{tabular}

Dari analisis kesenjangan yang telah dilakukan, maka dapat dibuatlah sebuah grafik kesenjangan tingkat kapabilitas proses seperti pada Gambar 5 di bawah ini:

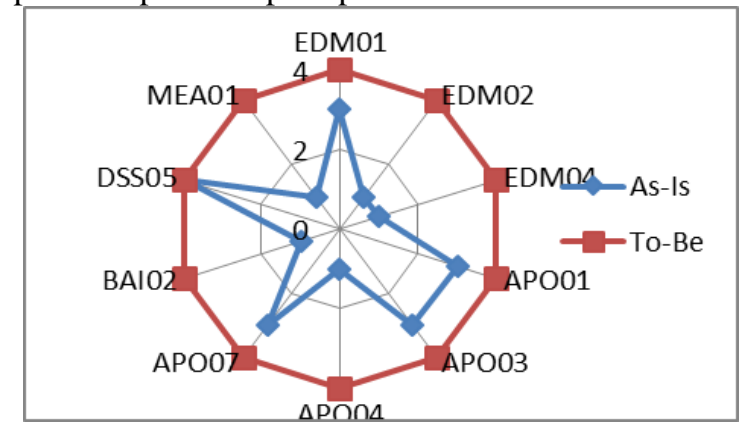

Gambar 5. Grafik Kesenjangan Tingkat Kapabilitas Proses

Berdasarkan jawaban dari rekapitulasi responden diperoleh rata-rata nilai kapabilitas level sebesar 2.3 dan memiliki gap sebesar 1.7 untuk mencapai nilai target 4 sebagai implementasi target STMIK-STIE Mikroskil.

\section{KESIMPULAN}

Setelah dilaksanakan proses evaluasi pada infrastruktur TI di STMIK-STIE Mikroskil maka hal yang perlu diperhatikan dalam penelitian ini adalah bahwa pemetaan dilakukan mulai dari melihat kebutuhan 
stakeholder ke tujuan tatakelola untuk mengoptimalkan sumber daya infrastruktur TI, lalu diambillah hubungan $\mathrm{P}$ (primer) dari tujuan tatakelola sehingga didapatkan tujuan organisasi. Lalu tujuan organisasi akan dipetakan ke tujuan terkait TI untuk nantinya dipetakan ke tujuan proses sehingga didapatkan proses yang akan dievaluasi yaitu EDM01, EDM02, EDM04, APO01, APO03, APO04, APO07, BAI02, DSS05 dan MEA01.

Dari 10 proses yang disebutkan sebelumnya kemudian dievaluasi dan didapatkan bahwa proses EDM002, EDM04, APO04, BAI02, MEA01 berada pada level 1. Sedangkan proses EDM01, APO01, APO03, APO07 berada pada level 3 dan proses DSS05 berada pada level 4.

Hal tersebut di atas bermakna bahwa target pencapaian yang ditetapkan Mikroskil adalah 4, di mana hasil perhitungan capability level pada saat ini adalah 2,30. Maka untuk mencapai level target terdapat gap sebesar 1,70. Untuk menutupi gap yang ada pada infrastruktur TI STMIK-STIE Mikroskil diperlukan pendokumentasiaan yang lebih baik lagi yang sesuai dengan COBIT 5 di mana ada beberapa output yang merupakan standar COBIT belum dimiliki oleh pihak Mikroskil walaupun aktifitasnya telah dilakukan oleh pihak Mikroskil.

Mikroskil saat ini menggunakan standar ISO9001:2008 untuk sistem dokumentasinya dan jika dilakukan pengelolaan berkelanjutan dengan standar COBIT 5 maka di masa mendatang hasil yang lebih baik akan diperoleh pihak STMIK-STIE Mikroskil dibandingkan dengan yang sudah ada sekarang karena COBIT 5 sesuai dengan ISO/IEC 15504.

\section{SARAN}

Untuk kedepannya, penelitian dapat dilanjutkan dengan melakukan studi kasus untuk proses lainnya seperti EDM03, APO09, APO10, APO11, APO12, APO13, BAI01, BAI04, BAI06, BAI10, DSS01, DSS02, DSS03, DSS04, DSS06, MEA02, MEA03 (Santosa, Candra, \& Widyawan, 2017) agar didapatkan rekomendasi yang lebih baik lagi untuk evaluasi tatakelola infrastruktur TI yang dimanfaatkan oleh STMIK-STIE Mikroskil.

STMIK-STIE Mikroskil juga diharapkan untuk menyusun dan menetapkan pedoman berdasarkan panduan dari COBIT 5 untuk proses yang dievaluasi.

\section{DAFTAR PUSTAKA}

Chanopas, A., Krairit, D. \& Khang, D. B., 2006. Managing Information Technology Infrastructure: A New Flexibility Framework. Management Research News, p. 21.

Hidayat \& Rahmat, A., 2015. Audit Control Capability Level Tata Kelola Sistem Informasi Menggunakan COBIT 5 (Studi: Direktorat TIK UPI Bandung). Jurnal Informasi, Nopember, VII(No.2), p. 15.

ISACA, 2011. COBIT 5: Process Reference Guide Exposure Draft. Rolling Meadows: www.isaca.org.

ISACA, 2012. A Business Framework for the Governance and Management of Enterprise IT. 6th ed. s.l.:s.n.

ISACA, 2012. COBIT 5: Enabling Processess. USA: s.n.

ISACA, 2013. Process Assessment Model (PAM): Using COBIT 5. USA: s.n.

Nugroho, H., 2013. Perancangan Model Kapabilitas Optimasi Sumber Daya TI Berdasarkan COBIT 5 Process Capability Model. Jurnal Teknologi Informasi, Mei, 1(No. 5), p. 8.

Purnomo, H., Fauziati, S. \& Winarno, W. W., 2016. Penilaian Tingkat Kapabilitas Proses Tata Kelola Teknologi Informasi dengan COBIT 5 pada Domain EDM (Studi Kasus di PT.Nusa Halmahera Minerals). Yogyakarta, Konferensi Nasional Teknologi Informasi dan Komunikasi (KNASTIK).

Ruslim, N., 2016. IT Governance Indonesia. [Online] Available at: https://itgid.org/prinsip-cobit-5/ [Accessed 5 November 2018].

Santosa, C. \& W., 2017. Pemetaan Penurunan Tujuan COBIT 5 Untuk Audit Keamanan Sistem Informasi (Studi Kasus: Sistem Informasi Akademik Sekolah Tinggi XYZ). p. 7.

Sarno, R., 2009. Audit Sistem dan Teknologi Informasi. Surabaya: ITS Press.

\section{UCAPAN TERIMA KASIH}

Peneliti mengucapkan terima kasih kepada STMIK-STIE Mikroskil yang bersedia untuk dijadikan sebagai objek penelitian sehingga peneliti dapat menyelesaikan penelitian dengan baik. 